Article

\title{
Public Acceptance of the "Renewable Energy 3020 Plan": Evidence from a Contingent Valuation Study in South Korea
}

\author{
Ju-Hee Kim, Sin-Young Kim and Seung-Hoon Yoo*(1) \\ Department of Energy Policy, Graduate School of Energy \& Environment, Seoul National University of Science \& \\ Technology, 232 Gongreung-Ro, Nowon-Gu, Seoul 01811, Korea; jhkim0508@seoultech.ac.kr (J.-H.K.); \\ sykim@seoultech.ac.kr (S.-Y.K.) \\ * Correspondence: shyoo@seoultech.ac.kr; Tel.: +82-2-970-6802
}

Received: 7 March 2020; Accepted: 4 April 2020; Published: 14 April 2020

\begin{abstract}
South Korea is promoting the "Renewable Energy 3020 Plan" to expand the proportion of renewable energy (RE) from $2.2 \%$ in 2016 to $20 \%$ in 2030 . Since the plan could lead to an increase in electricity rates, public acceptance of it is an important key to determining its success. This article examines the public acceptance of the plan by employing contingent valuation (CV). A nationwide CV survey of 1000 households was performed to collect the data on the willingness to pay (WTP) for implementing the plan using electricity charges as a payment vehicle during October 2018. More specifically, a dichotomous choice question to ask interviewees whether they have an intention of paying an offered bid and a spike model to treat the zero WTP observations were employed. The estimate for monthly WTP was KRW 3646 (USD 3.27) per household. When 10 years of the payment period presented in the survey and forecasted values of residential RE electricity consumption from 2018 to 2030 were used, the WTP was worth KRW 60.4 (USD 0.05) per kWh in 2018 constant price. The WTP amounts to 56.5\% of the price for residential electricity (KRW 106.9 or USD 0.10 per kWh). That is, the RE electricity produced through implementing the plan has a premium of $56.5 \%$ over the current electricity. Overall, it is concluded that public acceptance of the plan has been secured.
\end{abstract}

Keywords: public acceptance; renewable energy; contingent valuation; willingness to pay

\section{Introduction}

Most advanced countries have been expanding the proportion of renewable energy (RE) in their total generation, reducing nuclear power and coal-fired generation [1-4]. However, the share of RE in South Korea in 2016 was just 2.2\%. The country's ratios of coal-fired and nuclear power generation were $39.6 \%$ and $30.0 \%$ in 2016 , respectively, which together amount to $70 \%$. It has been forecasted that the percentage of coal-fired and nuclear power generation will be close to $80 \%$ in 2030 if no other actions are taken [5].

In May 2017, a new president was elected and made a major pledge to increase RE drastically. The South Korean government is implementing the "Renewable Energy 3020 Plan" to expand the proportion of RE generation from $2.2 \%$ in 2016 to $20 \%$ in 2030, reducing the proportion of coal-fired and nuclear power generation. The RE generation can abate particulate matters and greenhouse gases emissions produced by coal-fired power plants and enhance public safety related to nuclear power plants.

In spite of that, some people in the country are protesting against the "Renewable Energy 3020 Plan" for various reasons. In particular, the main criticism is that the promotion of the plan will lead to 
higher electricity prices, which will reduce industrial competitiveness and increase people's economic burden. As of 2018, the power generation costs for nuclear power, coal, natural gas, and RE are KRW 62.1, 81.8, 121.0, and 177.0 per kWh, respectively [6]. Although the costs for RE facilities are falling, local residents are less receptive to wind and solar power generation, and thus the actual costs of RE power generation are not as low as expected. Just as organic vegetables are more expensive than ordinary non-organic vegetables, electricity produced through RE should be more expensive than electricity based on nuclear and coal-fired power. However, South Koreans' willingness to shoulder additional costs seems unclear.

In summary, public acceptance of the "Renewable Energy 3020 Plan" is an important key to determining its success. Therefore, this study seeks to look into the public acceptance of the plan by applying contingent valuation (CV). CV has been widely employed for assessing the economic benefits of non-market goods, such as the advantages arising from expanding RE generation, in the literature [7-13].

For example, Yoo and Kwak [7] found that the monthly mean household's willingness to pay (WTP) estimates for green electricity in South Korea from parametric and non-parametric methods were KRW 1681 (USD 1.8) and KRW 2072 (USD 2.2), respectively. Kwak and Yoo [8] discovered that the monthly mean WTP for ocean energy in South Korea was KRW 1003 (USD 0.9) per household. Guo et al. [9] estimated the mean WTP for RE from Beijing residents of China as USD 2.7 to 3.3 per household per month. Lee et al. [10] estimated consumers' additional WTP for replacing traditional energy generated from nuclear and coal sources with RE in South Korea as USD 3.3 and USD 3.0, respectively, per month. Zografakis et al. [12] obtained the mean WTP for RE from a survey of Crete residents of Greece as EUR 16.33 per household per quarter as an additional charge for the electricity bill. Nomura and Akai [13] observed that Japanese households' monthly WTP for RE was USD 17.

The key findings from this research will not only provide implications for the government's continued implementation of the plan but will also help to identify what should be borne in mind when pursuing the plan. A CV survey was administered to 1000 households across the country to collect the data on their willingness to pay (WTP) for implementing the plan using electric charges as a payment vehicle during October 2018. A professional survey company performed the survey through in-person face-to-face interviews. The dichotomous choice question was adopted to ask interviewees whether they have an intention of paying an offered bid. Moreover, a spike model was applied to analyze the observations with a large number of zeros.

The implications of the study will be useful, because the government desperately needs information about the public acceptance of the plan. There are three sections in the rest of this study. An explanation of the methodology is given in Section 2. In particular, the theoretical background and application procedures of the $\mathrm{CV}$ technique, the main technique used in this study, are presented. Section 3 explains the data, addresses the results, and reports discussion of the results. Conclusions are made in the last section.

\section{Methodology}

\subsection{Method: CV Technique}

Obtaining the demand function for a non-market good is quite a complicated work. Because there are no transaction data for the good in the market, the data that are necessary for obtaining the demand function are not available [14]. According to microeconomic theory, the lower area of the demand function implies WTP $[15,16]$. In fact, when dealing with non-market goods, information about the lower area of the demand function is needed, that is, the benefits from the consumption of non-market goods or the economic value provided by non-market goods, rather than the demand function itself [17]. The methods applied to obtain that information can largely be divided into the stated preference (SP) technique and the revealed preference (RP) technique [18]. 
The RP method observes and analyzes the results of a person's behavior as an ex post technique. On the other hand, the SP technique examines the data obtained after asking people for their preferences as an ex ante technique. The two techniques have their own advantages and disadvantages, but, in theory, the SP approach is more accurate and the RP approach is limited in terms of the range of objects to be assessed [19]. Therefore, judging from the literature, more studies have applied the SP approach than the RP approach.

One widely used SP approach in the empirical literature is the CV method [20-25]. The term "contingent" means a situation in which potential consumers of a non-market good are drawn into a hypothetical market in which the non-market goods can be recognized as being traded and then place a value on the good [19]. Thus, it is necessary to define clearly the current state of reference and the target state to be valued to apply the CV method [11]. In addition, the process of collecting data through a survey is essential to the application of the CV method. For this reason, understanding the survey methodology and familiarity with microeconomic theory are important in applied CV work [26].

In particular, a seminal paper of Arrow et al. [27] presented some methodological guidelines that applied CV researches should follow. For example, they include the use of in-person face-to-face interviews instead of mail or telephone interviews during a survey, the adoption of a sample size of at least 1000, a description of some substitutable goods for the object under investigation, and the use of WTP rather than willingness to accept as a question format for valuing a non-market good. Johnston et al. [28] also discussed guidelines to follow when applying the SP method, including CV. As will be explained below, this study tried to follow most of these guidelines.

\subsection{Survey Questionnaire and Field Survey}

The first step in creating a survey questionnaire is to define accurately the goods to be evaluated. This involves identifying the business-as-usual (BAU) state $\left(Q_{0}\right)$ and the target state $\left(Q_{1}\right)$ and clarifying the various policy measures for moving from the BAU to the target states. In this study, the BAU state means the state in which no additional action is taken by the government. The target status refers to the goal for which the government wants to take action to reach, that is, ultimately the goal to evaluate. Thus, the goods under evaluation indicate the difference between $Q_{1}$ and $Q_{0}$ rather than the target state $\left(Q_{1}\right)$ itself. In other words, the difference between doing something and doing nothing is assessed in an applied CV study.

In this study, the BAU state is that the share of RE generation in South Korea in 2016 was $2.2 \%$ and the target state is expanding the proportion of RE generation to $20 \%$ by 2030 . The policy measures for moving from the BAU state to the target state are as follows:

- To fulfill the target state, the government plans to push ahead gradually with the installation project of large-scale RE facilities, taking into consideration public acceptance and the environmental effect;

- to introduce a planned location system that secures public acceptance and the environmental effect in advance and shares the development benefits; and

- to create an environment in which the public can easily participate in the solar power business.

There were three main parts in the questionnaire. The first part slowly led respondents to the hypothetical market, asking about their general perception of and experience associated with the goods being evaluated. The second part described the current state, the target state, and the policy measures for moving from $Q_{0}$ to $Q_{1}$ and then asked the respondents about their WTP. Before asking the WTP question, "As of 2018, the power generation costs for nuclear power, coal, natural gas, and RE are KRW 62.1, 81.8, 121.0, and 177.0 per $\mathrm{kWh}$, respectively" was explained to the respondents as background information. In particular, the point that the generation cost for nuclear power is almost one-third of that for RE was clearly stated in the CV survey in order to help the interviewees to make well-informed decisions.

The last part asked them about their socioeconomic characteristics and those of their household, such as their education level, income level, age, and gender. The initial version of the questionnaire 
needed to be checked for readability, and thus this study refined it after performing a pre-survey with a 30-member focus group. In other words, final corrections to the questionnaire were made by checking whether there was anything that was difficult to understand, whether there was anything that was not clear, and whether there were any possible changes to the wording that might make the questionnaire easier to understand.

The survey method must be determined for a field survey. Usually, four types are utilized, being postal surveys, telephone surveys, person-to-person interviews, and Internet surveys. While postal surveys have low-cost advantages, the response rate is relatively low in South Korea and the sample may be biased to one side because only respondents with a particular propensity might respond. For telephone surveys, the cost is reasonable and random dialing methods, including mobile phones, allow random sampling. However, it is difficult to present enough information to the respondents to create a hypothetical market. More and more affordable Internet surveys are being conducted these days as Internet penetration increases, but there is a high possibility of obtaining a selected sample rather than a random one. Person-to-person interviews have the disadvantage of high cost but the advantage of being able to ensure a random sample and present in full the information needed to immerse the respondents in the hypothetical market. Furthermore, the respondents can give answers conveniently through skilled professional interviewers. Therefore, this study employed person-to-person interviews.

\subsection{How to Elicit WTP Responses}

The methods of eliciting WTP in CV studies can largely be divided into open- and closed-ended question formats. If the open-ended question format is used, interviewees are directly requested to report their WTP responses in a continuous value. Respondents may be embarrassed when open-ended questions are asked, which may increase their objection to the survey itself or the probability of reporting protest responses. However, if the closed-ended question format is adopted, interviewees are asked about whether they have an intention of paying a presented bid or not. Thus, the use of the closed-ended enables us to avoid the problem of protest responses.

Using the open-ended question format can obtain continuous point WTP data. However, the closed-ended question format produces discrete response data of "yes" or "no", that is, interval data of WTP. In terms of statistical efficiency, continuous data are superior to interval data, but, in terms of the reliability of response data, the closed-ended question is known to be superior to the open-ended question [19]. Therefore, the closed-ended question was applied in this study. The use of the closed-ended question enables us to avoid respondents' strategic behavior which means that they may overstate or understate her/his WTP [19].

In particular, among several closed-ended questions the single-bounded (SB) question proposed by Hanemann [29] is used in this study because of its ability to ensure consistency despite the disadvantage of low efficiency. For the application of the SB question format, sets of bid amounts must be determined in advance. Let $R$ be the number of respondents and $T_{r}$ be a bid offered to respondent $r$ for $r=1, \ldots, R$. When the bid $\left(T_{r}\right)$ is presented, if the response is "yes", WTP $r>T_{r}$, and, if the response is "no," $W T P_{r} \leq T_{r}$. A binary variable representing the two cases can be defined as:

$$
B_{r}^{Y}=I(r \text { th interviewee's answer is "no" })
$$

where $I(\cdot)$ becomes one when the argument is true and zero when the argument is not true.

\subsection{Econometric Model for Analyzing the WTP Responses}

The spike model is quite useful when dealing with closed-ended CV data with many zero values $[14,30,31]$. The SB spike model, which is an econometric model for analyzing WTP responses with zero observations, was employed in this research and is described below. Let the bid amount presented to respondent $r$ be $T_{r}$ for $r=1, \cdots, R$. In order to identify respondents with WTP $=0$, 
the interviewers further asked those who responded "no" to the amount $\left(T_{r}\right)$ whether they are willing to pay anything or nothing, that is, whether their WTP is greater than zero or zero. One more binary variable indicating possible outcomes from the further question is:

$$
B_{r}^{T Y}=I(r \text { th interviewee's answer to the further question is "yes" })
$$

Therefore, there are three possible cases. If the response is "no-no", WTP $=0$, if the response is "no-yes," $0<W T P \leq T_{r}$, and, if the response is "yes," WTP $>T_{r}$. Let $H_{W T P}(\cdot)$ be the cumulative distribution of WTP. Employing the logistic function commonly used in the literature, the following form can be derived for $H_{W T P}(\cdot)$.

$$
H_{W T P}\left(T ; \pi_{0}, \pi_{1}\right)=\left\{\begin{array}{cc}
{\left[1+\exp \left(\pi_{0}-\pi_{1} T\right)\right]^{-1}} & \text { if } T>0 \\
{\left[1+\exp \left(\pi_{0}\right)\right]^{-1}} & \text { if } T=0 \\
0 & \text { if } T<0
\end{array}\right.
$$

where $\pi_{0}$ and $\pi_{1}$ are parameters to be estimated.

In particular, the probability that WTP is zero is called the spike. Therefore, the spike is computed as $\left[1+\exp \left(\pi_{0}\right)\right]^{-1}$. The formula computing the mean WTP is obtained as $\left(1 / \pi_{1}\right) \ln \left[1+\exp \left(\pi_{0}\right)\right]$ from combining the general equation that obtains the mean using the cumulative distribution function and Equation (3). The spike model takes the following form of log-likelihood function:

$$
\begin{aligned}
\ln L=\sum_{r=1}^{R}\left\{B_{r}^{Y} \ln [1\right. & \left.-H_{W T P}\left(T_{r} ; \pi_{0}, \pi_{1}\right)\right] \\
& +B_{r}^{T Y}\left(1-B_{r}^{Y}\right) \ln \left[H_{W T P}\left(T_{r} ; \pi_{0}, \pi_{1}\right)-H_{W T P}\left(0 ; \pi_{0}, \pi_{1}\right)\right] \\
& \left.+\left(1-B_{r}^{T Y}\right)\left(1-B_{r}^{Y}\right) \ln H_{W T P}\left(0 ; \pi_{0}, \pi_{1}\right)\right\}
\end{aligned}
$$

One can obtain the maximum likelihood estimates for $\pi_{0}$ and $\pi_{1}$ by maximizing Equation (4) with respect to $\pi_{0}$ and $\pi_{1}$. The variables representing respondents' characteristics are called covariates. The impact that covariates make on the probability of their reporting "yes" to the presented bid with the model containing covariates can be examined. Replacing $\pi_{0}$ with $\pi_{0}+y_{r}^{\prime} \omega$ in Equations (3) and (4) gives us the model with covariates, where $y_{r}$ and $\omega$ indicate covariates and their coefficients.

\section{Results}

\subsection{Data}

As explained above, it is necessary to take the utmost care in collecting data through a CV survey. In this regard, four important considerations have been taken into account in this study.

- First, the sample size was set at 1000. This is because Arrow et al. [27] proposed 1000 as the number of observations needed for policy decision making and the Korea Development Institute, a government-run think tank, also provided a guideline of 1000 for the size of nationwide sample needed for policy decision making.

- Second, an attempt was made to make the sample representative of the population by sampling based on the census data gathered in 2015 by Statistics Korea [32]. In this regard, the sample and population characteristics are compared in Table 1. There does not seem to exist any significant gap between the values for the sample and those for the population.

- Third, a professional polling firm was commissioned to conduct the survey to ensure fairness in sampling and implement face-to-face surveys, despite their high cost.

- Fourth, the electricity bill was chosen as a payment vehicle to help respondents reveal their actual WTP without difficulty. An appropriate payment vehicle can avoid any bias caused by hypothetical question. This is because in a hypothetical market situation, respondents may take 
the experiment less seriously than in a real situation. In addition, the payment period presented in the CV survey was 10 years.

Table 1. Sample and population characteristics.

\begin{tabular}{ccc}
\hline Variables & Sample & Population ${ }^{\mathbf{b}}$ \\
\hline Gender & & \\
Female & $50.0 \%$ & $49.9 \%$ \\
Male & $50.0 \%$ & $50.1 \%$ \\
Region & & \\
\hline Seoul & $20.1 \%$ & $19.4 \%$ \\
Pusan & $7.2 \%$ & $7.0 \%$ \\
Daegu & $5.0 \%$ & $4.8 \%$ \\
Incheon & $5.7 \%$ & $5.6 \%$ \\
Gwangju & $2.9 \%$ & $3.0 \%$ \\
Daejeon & $3.0 \%$ & $3.1 \%$ \\
Ulsan & $2.3 \%$ & $2.2 \%$ \\
Sejong & $0.4 \%$ & $0.6 \%$ \\
Gyunggi & $23.9 \%$ & $23.7 \%$ \\
Gangwon & $3.1 \%$ & $3.2 \%$ \\
Chungbuk & $3.1 \%$ & $3.2 \%$ \\
Chungnam & $4.1 \%$ & $4.3 \%$ \\
Jeonbuk & $3.7 \%$ & $3.8 \%$ \\
Jeonnam & $3.6 \%$ & $3.8 \%$ \\
Gyungbuk & $5.4 \%$ & $5.6 \%$ \\
Gyungnam & $6.5 \%$ & $6.7 \%$ \\
Household income & KRW 4.91 million & KRW $4.83 \mathrm{million}$ \\
\hline
\end{tabular}

Notes: ${ }^{a}$ The number of respondents is $1000 .{ }^{b}$ comes from Statistics Korea [32]. ${ }^{c}$ means the average.

In summary, a professional survey company in the country conducted a survey of 1000 households aged 20 to 65 years to collect the data during October 2018. Judging from the comments of the supervisor and interviewers who belonged to the company, the CV survey was implemented without difficulty and successful enough to collect the opinions of respondents who can represent the population.

The distribution of answers provided by interviewees to the suggested bid is given in Table 2 . Each bid that is shown in the first column of Table 2 was offered to a similar number of interviewees. If the answer to whether or not to pay the bid is "no," a further question is asked to confirm whether the interviewee's WTP ranges from zero to the bid or zero. Of the 1000 interviewees, 491 persons provided "no-no" response. They have no intention of paying a single cent for implementing the "Renewable Energy 3020 Plan". Thus, "no-no" answer implies zero WTP.

Table 2. Distribution of answers to presented bid.

\begin{tabular}{|c|c|c|c|c|}
\hline Bid Amount ${ }^{a}$ & "Yes" & “No-Yes" & "No-No" & Totals \\
\hline 1000 & $111(66.5)$ & $16(9.6)$ & $40(24.0)$ & 167 (100.0) \\
\hline 2000 & 75 (44.9) & $28(16.8)$ & $64(38.3)$ & 167 (100.0) \\
\hline 3000 & $50(30.1)$ & 31 (18.7) & 85 (51.2) & $166(100.0)$ \\
\hline 5000 & $44(26.3)$ & $28(16.8)$ & $95(56.9)$ & $167(100.0)$ \\
\hline 7000 & $36(21.7)$ & 33 (19.9) & 97 (58.4) & $166(100.0)$ \\
\hline 10,000 & 17 (10.2) & $40(24.0)$ & $110(65.9)$ & $167(100.0)$ \\
\hline Totals & 333 (33.3) & $176(17.6)$ & $491(49.1)$ & $1000(100.0)$ \\
\hline
\end{tabular}

Notes: ${ }^{a}$ Unit is Korean won (USD $1=$ KRW 1114.5). Figures in the parentheses beside the number of answers indicate the percentage of the answers. 


\subsection{Estimation Results}

The findings from estimating the model are contained in Table 3. By performing maximum likelihood estimation, the parameter estimates for the model could be obtained. Concerning the model specification test, the Wald statistic can be computed. The hypothesis to be tested is that the model is insignificant or meaningless. The statistic and its $p$-value are 212.26 and 0.000 , respectively, which implies that the hypothesis can be rejected. Consequently, the model has statistical significance. Interestingly, the estimate for the spike (0.4944) is close to the sample ratio of "no-no" answers $(49.1 \%)$, which collaborates the usefulness of the spike model.

Table 3. Results of estimating the model.

\begin{tabular}{|c|c|}
\hline Variables & Coefficient Estimates ( $t$-Values) \\
\hline Constant & $0.0224(0.35)^{\#}$ \\
\hline Bid amount $^{\text {a }}$ & $-0.1932(-14.96) \#$ \\
\hline Spike & $0.4944(31.15) \#$ \\
\hline Mean household willingness to pay per month & KRW 3646 (USD 3.27) \\
\hline$t$-value & $14.57^{\#}$ \\
\hline $95 \%$ confidence interval $^{b}$ & KRW 3208 to 4200 (USD 2.88 to 3.77 ) \\
\hline $99 \%$ confidence interval ${ }^{b}$ & KRW 3090 to 4402 (USD 2.77 to 3.95 ) \\
\hline Sample size & 1000 \\
\hline Log-likelihood & -992.98 \\
\hline Wald statistic $(p \text {-value })^{\mathrm{C}}$ & $212.26(0.000)$ \\
\hline
\end{tabular}

Notes: ${ }^{a}$ Unit is Korean won. ${ }^{\mathrm{b}}$ Calculated using Krinsky and Robb's [33] method. ${ }^{\mathrm{c}}$ Null hypothesis is that the model is insignificant or meaningless. ${ }^{\#}$ indicates statistical significance at a significance level of $1 \%$.

The estimate for mean household WTP was derived as KRW 3646 (USD 3.27) per month. The estimate's confidence intervals for 95 and $99 \%$ levels can be calculated from the procedure shown in Krinsky and Robb's [33] paper. More specifically, 5000 replications of resampling the parameters from bi-variate normal distribution constructed with the estimation results of $\pi_{0}$ and $\pi_{1}$ produce the confidence intervals, as reported in Table 3.

\subsection{Findings from Estimating the Model With Covariates}

The spike model with covariates can be introduced for investigating the impact that covariates make on the possibility of responding "yes" to an offered bid. Concerning the covariates, three variables related to the respondents' characteristics were selected. Basic information about the covariates are reported in Table 4 . The findings from estimating the model with covariates are described in Table 5.

Table 4. Basic information about variables used for covariates.

\begin{tabular}{cccc}
\hline Variables & Definitions & Mean & Standard Deviation \\
\hline Income & $\begin{array}{c}\text { The interviewee's household income } \\
\text { (unit: million Korean won) } \\
\text { The interviewee's age }\end{array}$ & 493.88 & 208.24 \\
Education & $\begin{array}{c}\text { The interviewee's education level's being higher } \\
\text { than high school graduate }(0=\text { no; } 1=\text { yes) }\end{array}$ & 47.12 & 9.31 \\
\hline
\end{tabular}

All the estimated values possessed statistical significance. The positive sign of the estimated coefficient implies that the greater the covariate, the greater the possibility of saying "yes" to an offered bid. The figures for income and education variables were positive. However, the figure for Age variable was negative. Households with more income had a higher possibility to report "yes" to a presented bid than households with less income. The education level of the interviewee had a positive correlation to the probability of stating "yes". Older interviewees had less likelihood of providing "yes" answer than younger ones. 
Table 5. Estimation results of the model with covariates.

\begin{tabular}{|c|c|}
\hline Variables $^{\text {a }}$ & Coefficient Estimates ( $t$-Values) \\
\hline Constant & $-0.4689(-2.07) \#$ \\
\hline Bid amount ${ }^{b}$ & $-0.1991(-14.53) \#$ \\
\hline Income & $0.4540(2.09) \#$ \\
\hline Age & $-0.4953(-3.14)^{\#}$ \\
\hline Education & $0.3536(2.57) \#$ \\
\hline Spike & $0.4947(31.01))^{\#}$ \\
\hline Mean household willingness to pay per month & KRW 3535 (USD 3.17) \\
\hline$t$-value & $14.06^{\#}$ \\
\hline $95 \%$ confidence interval $^{c}$ & KRW 3103 to 4078 (USD 2.78 to 3.66 ) \\
\hline $99 \%$ confidence interval ${ }^{c}$ & KRW 2992 to 4308 (USD 2.68 to 3.87 ) \\
\hline Sample size & 1000 \\
\hline Log-likelihood & -974.71 \\
\hline Wald statistic ( $p$-value $)^{\mathrm{d}}$ & $197.53(0.000)$ \\
\hline
\end{tabular}

Notes: ${ }^{\text {a }}$ Table 4 explains the variable. ${ }^{\mathrm{b}}$ Unit is Korean won. ${ }^{\mathrm{c}}$ Calculated using Krinsky and Robb's [33] method. ${ }^{d}$ Null hypothesis is that the model is insignificant or meaningless. ${ }^{\#}$ means statistical significance at a significance level of $1 \%$.

\subsection{Discussion of the Results}

The benefits ensuing from implementing the "Renewable Energy 3020 Plan" were presented in monetary units per $\mathrm{kWh}$. The target state of this study is to implement the plan to expand the proportion of RE generation to $20 \%$ by 2030 . As explained above, the estimate for the mean household WTP per month, KRW 3646 (USD 3.27), means the economic benefits of expanding the ratio of RE to $20 \%$ by 2030 . In order to change the unit of economic benefits to $\mathrm{kWh}$, it is necessary to calculate the RE consumption from 2018 to 2030.

To this end, the data on electricity consumption, which are based on the target demand set out in the national plan made by the government [34] was used. The residential power consumption amounts to $13.5 \%$ of total power consumption in 2017 [6]. It is assumed that this ratio of $13.5 \%$ will be maintained until 2030. Multiplying the total electricity consumption by the ratio of residential power consumption, the residential electricity consumption could be calculated. The ratio of RE to total power generation from 2018 to 2029 was estimated by employing a linear interpolation method using data on the 2030 target of $20 \%$ and the 2016 performance of $2.2 \%$, as suggested in the plan. With the result of multiplying the residential electricity consumption by the ratio of RE, the total RE consumption from 2018 to 2030 was calculated to be 123,005 GWh. Table 6 reports the detailed procedure of the calculation.

The procedures and results of computing the economic benefits of the residential electricity sector ensuing from implementing the "Renewable Energy Plan 3020" using the estimate for mean household WTP per year for increasing the proportion of RE generation to $20 \%$ by 2030 are presented in Table 7 . In the course of the computation, an appropriate social discount rate should be determined. In this regard, the latest social discount rate recommended by the government is $4.5 \%$, which is used here. Thus, the discounted annual total economic benefits that occur for 10 years from 2018 to 2027 was computed as about KRW 7.4 trillion (USD 6.7 billion) in 2018 constant price.

This value is related to replacing a total of 123 TWh of residential power consumption from 2018 to 2030 with RE. Therefore, the WTP per kWh of electricity becomes KRW 60.4 (USD 0.05) in 2018 constant price, as shown in Table 8 . This value is worth $56.5 \%$ of the electricity price, which was KRW 106.9 (USD 0.10) per kWh in 2018, and interpreted as a price premium for RE power. The country's public is in favor of the expansion of the proportion of RE generation. The government should actively promote the "Renewable Energy Plan 3020". 
Table 6. Renewable energy consumption from 2018 to 2030.

\begin{tabular}{|c|c|c|c|c|c|}
\hline Year & $\begin{array}{l}\text { Total Electricity } \\
\text { Consumption a } \\
\text { (A, Unit: GWh) }\end{array}$ & $\begin{array}{c}\text { Ratio of Residential } \\
\text { Electricity } \\
\text { Consumption b } \\
\text { (B) }\end{array}$ & $\begin{array}{c}\text { Residential Electricity } \\
\text { Consumption } \\
(\mathrm{C}=\mathrm{A} \times \mathrm{B}, \text { Unit: } \mathrm{GWh})\end{array}$ & $\begin{array}{l}\text { Ratio of } \\
\text { Renewable } \\
\text { Energy }^{c} \\
\text { (D) }\end{array}$ & $\begin{array}{c}\text { Residential } \\
\text { Consumption of } \\
\text { Electricity from } \\
\text { Renewable Energy } \\
(\mathrm{E}=\mathrm{C} \times \mathrm{D}, \text { Unit: } \mathrm{GWh})\end{array}$ \\
\hline 2018 & 519,069 & $13.5 \%$ & 70,074 & $4.7 \%$ & 3324 \\
\hline 2019 & 530,358 & $13.5 \%$ & 71,598 & $6.0 \%$ & 4306 \\
\hline 2020 & 540,054 & $13.5 \%$ & 72,907 & $7.3 \%$ & 5312 \\
\hline 2021 & 548,898 & $13.5 \%$ & 74,101 & $8.6 \%$ & 6341 \\
\hline 2022 & 556,088 & $13.5 \%$ & 75,072 & $9.8 \%$ & 7378 \\
\hline 2023 & 561,700 & $13.5 \%$ & 75,830 & $11.1 \%$ & 8417 \\
\hline 2024 & 566,228 & $13.5 \%$ & 76,441 & $12.4 \%$ & 9457 \\
\hline 2025 & 569,824 & $13.5 \%$ & 76,926 & $13.6 \%$ & 10,495 \\
\hline 2026 & 572,800 & $13.5 \%$ & 77,328 & $14.9 \%$ & 11,533 \\
\hline 2027 & 575,229 & $13.5 \%$ & 77,656 & $16.2 \%$ & 12,569 \\
\hline 2028 & 577,029 & $13.5 \%$ & 77,899 & $17.5 \%$ & 13,599 \\
\hline 2029 & 578,515 & $13.5 \%$ & 78,100 & $18.7 \%$ & 14,627 \\
\hline 2030 & 579,547 & $13.5 \%$ & 78,239 & $20.0 \%$ & 15,648 \\
\hline Totals & 7275,339 & & 982,171 & & 123,005 \\
\hline
\end{tabular}

Notes: ${ }^{a}$ Values are taken from Ministry of Trade, Industry, and Energy [34]. ${ }^{\mathrm{b}}$ It was assumed that $13.5 \%$ of the actual value for 2017 presented in Korea Electric Power Corporation [6] would be maintained until 2030. ${ }^{\mathrm{c}}$ The proportion of renewable energy from 2018 to 2029 was estimated using the linear interpolation method using $2.2 \%$ of actual value for 2016 and 20\% of the 2030 target set forth in "Renewable Energy Plan 3020".

Table 7. Economic benefits of the residential electricity sector ensuing from "Renewable Energy Plan 3020".

\begin{tabular}{|c|c|c|c|c|}
\hline Year & $\begin{array}{c}\text { Expected } \\
\text { Number of } \\
\text { Households }^{\text {a }}\end{array}$ & $\begin{array}{l}\text { Annual Economic } \\
\text { Benefits per Household }{ }^{b} \\
\text { (Unit: Korean Won) }\end{array}$ & $\begin{array}{c}\text { Annual Total } \\
\text { Economic Benefits } \\
\text { (Unit: Million Korean Won) }\end{array}$ & $\begin{array}{l}\text { Discounted Annual Total } \\
\text { Economic Benefits }{ }^{c} \\
\text { (Unit: Million Korean Won) }\end{array}$ \\
\hline 2019 & $19,971,359$ & 43,752 & 873,787 & 836,160 \\
\hline 2020 & $20,174,317$ & 43,752 & 882,667 & 808,284 \\
\hline 2023 & $20,714,305$ & 43,752 & 906,292 & 727,255 \\
\hline 2024 & $20,869,265$ & 43,752 & 913,072 & 701,144 \\
\hline 2025 & $21,013,656$ & 43,752 & 919,389 & 675,594 \\
\hline 2026 & $21,156,816$ & 43,752 & 925,653 & 650,905 \\
\hline 2027 & $21,290,091$ & 43,752 & 931,484 & 626,800 \\
\hline
\end{tabular}

Notes: ${ }^{\text {a }}$ Values are taken from Statistics Korea [32]. ${ }^{\mathrm{b}}$ Derivation of the value is explained in the text. ${ }^{\mathrm{c}}$ Social discount rate is $4.5 \%$, which is recommended by Korea Ministry of Strategy and Finance.

Table 8. Economic benefits of renewable energy consumption resulting from "Renewable Energy Plan 3020."

\begin{tabular}{ccc}
\hline $\begin{array}{c}\text { Present Value of Discounted } \\
\begin{array}{c}\text { Annual Total Economic Benefits } \\
\text { (A, Unit: Million Korean Won) }\end{array}\end{array}$ & $\begin{array}{c}\text { Renewable Energy } \\
\text { Consumption b } \\
\text { (B, Unit: GWh) }\end{array}$ & $\begin{array}{c}\text { Economic Benefits of One kWh of } \\
\text { Renewable Energy Consumption } \\
\text { (A/B, Unit: Korean Won per kWh) }\end{array}$ \\
\hline 7424,965 & 123,005 \\
\hline
\end{tabular}

\section{Conclusions}

To actively join international efforts to reduce greenhouse gas emissions in response to climate change, South Korea is promoting a plan of expanding the percentage of RE generation from $2.2 \%$ in 2017 to $20 \%$ in 2030 . The implementation of the plan requires public support because it will require a considerable amount of additional cost. This study examined public acceptance of the plan, 
investigating the results from a nationwide CV survey of 1000 of the country's households. The estimate for mean household WTP per month for implementing the plan was statistically significantly obtained as KRW 3646 (USD 3.27).

Using several assumptions, this value was estimated to be KRW 60.4 per (USD 0.05) kWh, which is $56.5 \%$ of the average price for residential electricity. In other words, South Korean households on average recognized the $56.5 \%$ level of current electricity price as a price premium for RE that will be significantly expanded than now. Of course, $49.1 \%$ of respondents expressed zero WTP for RE expansion. Despite this, since the mean WTP was estimated using a model that fully took this into account, the results of this study can be representative of the population as a whole. After comprehensively analyzing the value judgements of both those who gave zero value to the expansion of RE and those who placed significant value on the expansion of RE, we found that people gave a significant price premium to the expansion of RE. Therefore, it can be concluded that the public's acceptance of expanding RE was secured and the benefits ensuing from the expansion were significant.

The findings from the study are judged to be meaningful from the perspective of research as well as policy. This study has three important policy implications. First, the amount of each household's WTP for the government's ambitious "Renewable Energy 3020 Plan" was assessed quantitatively. Since the plan could lead to an increase in electricity prices, the government needs to figure out how much more the public can afford to pay for implementing the plan, which this study provided. Second, the price premium for the economic benefits of RE was measured quantitatively. As the public utilities are planning various types of RE development projects, it is necessary to undertake an economic feasibility analysis. In doing so, the essential information is the economic benefit of RE, which was computed to be about 1.565 times higher than the current electricity rate level. Third, it was found that $49.1 \%$ of households have no intention of making additional payments. After all, half of the households in the total were judged to have a negative attitude toward the plan. This suggests that the government needs to persuade people more actively and rationally to ensure the successful implementation of the plan.

This study also has several implications in terms of research. First, the CV technique has been successfully employed to look into the public acceptance of the "Renewable Energy 3020 Plan". The CV survey was conducted successfully with the respondents with little difficulty. In addition, both the estimates for both the parameters and the WTP possessed statistical significance. Second, the usefulness of the SB question format for eliciting WTP responses was confirmed. Since the SB question format asks a respondent just one question regarding whether she/he has an intention of paying a specified bid, it is quite simple and incentive compatible for the respondent to answer the question easily without any cognitive burden. Moreover, it does not suffer from any response effects that may distort the WTP responses. The interviewers commented that the interviewees answered the SB question effectively. Third, the spike model employed to allow for zero WTP values was well fitted to the data. Considering that a number of zero WTP responses have often been observed in the country, it was confirmed that the spike model can be useful in such cases.

The structure or methodology adopted in this study may be improved by follow-up studies in three aspects. First, if more observations are obtained through additional budgeting, regional analysis could lead to regionally differentiated implications. This is because the acceptance of the plan may vary depending on the region. For example, since regions that produce a lot of RE power are different from regions that consume a lot of RE power, the acceptability of the plan can differ between the two types of regions. Second, it is necessary to carefully estimate the additional costs incurred to implement the plan and then check which is larger when comparing the costs with the price premium of RE obtained in this study. If the former is smaller than the latter, the push for the plan could easily gain momentum. If not, other measures need to be taken, as it will be difficult for the plan to gain momentum. Third, this study adopted a conservative approach that does not distinguish true zero WTP from a protest bid response and regards both responses as zero WTP responses, but how the mean WTP estimate changes when following other approaches needs to be examined. 
Author Contributions: All three authors played their own significant roles in planning and writing this article. J.-H.K. proposed ideas for the article, laid out the basic framework for the survey, and wrote half of the article; S.-Y.K. finalized making the questionnaire and analyzed the model using the collected data; and S.-H.Y. supervised the research, wrote part of the article, and refined the entire article. All authors have read and agreed to the published version of the manuscript.

Funding: This work was supported by the Korea Institute of Energy Technology Evaluation and Planning (KETEP) and the Ministry of Trade, Industry \& Energy (MOTIE) of the Republic of Korea (No. 20184030202230).

Conflicts of Interest: The authors declare no conflict of interest.

\section{References}

1. Takase, K.; Suzuki, T. The Japanese energy sector: Current situation, and future paths. Energy Policy 2011, 11, 6731-6744. [CrossRef]

2. Jacobson, M.Z.; Delucchi, M.A.; Bazouin, G.; Bauer, Z.A.; Heavey, C.C.; Fisher, E.; Morris, S.B.; Piekutowski, D.J.Y; Vencill, T.A.; Yeskoo, T.W. 100\% clean and renewable wind, water, and sunlight (WWS) all-sector energy roadmaps for the 50 United States. Energy Environ. Sci. 2015, 8, 2093-2117. [CrossRef]

3. Yazdanpanah, M.; Forouzani, M. Application of the theory of planned behaviour to predict Iranian students intention to purchase organic food. J. Clean. Prod. 2015, 107, 342-352. [CrossRef]

4. Chapman, A.J.; Itaoka, K. Energy transition to a future low-carbon energy society in Japan's liberalizing electricity market: Precedents, policies and factors of successful transition. Renew. Sustain. Energy Rev. 2018, 81, 2019-2027. [CrossRef]

5. Korea Ministry of Trade, Industry, and Energy. The 7th Basic Plan for Long-Term Electricity Supply and Demand (2015-2029); Korea Ministry of Trade, Industry, and Energy: Sejong, Korea, 2015.

6. Korea Electric Power Corporation. Statistics of Electric Power in Korea; Korea Electric Power Corporation: Naju, Korea, 2018.

7. Yoo, S.H.; Kwak, S.Y. Willingness to pay for green electricity in Korea: A contingent valuation study. Energy Policy 2009, 37, 5408-5416. [CrossRef]

8. Kwak, S.Y.; Yoo, S.H. The public's value for developing ocean energy technology in the Republic of Korea: A contingent valuation study. Renew. Sustain. Energy Rev. 2015, 43, 432-439. [CrossRef]

9. Guo, X.; Liu, H.; Mao, X.; Jin, J.; Chen, D.; Cheng, S. Willingness to pay for renewable electricity: A contingent valuation study in Beijing, China. Energy Policy 2014, 68, 340-347. [CrossRef]

10. Lee, C.Y.; Lee, M.K.; Yoo, S.H. Willingness to pay for replacing traditional energies with renewable energy in South Korea. Energy 2017, 128, 284-290. [CrossRef]

11. Bigerna, S.; Polinori, P. The Economic Valuation of Green Electricity; Springer: Dordrecht, The Netherlands, 2019.

12. Zografakis, N.; Sifaki, E.; Pagalou, M.; Nikitaki, G.; Psarakis, V.; Tsagarakis, K.P. Assessment of public acceptance and willingness to pay for renewable energy sources in Crete. Renew. Sustain. Energy Rev. 2010, 14, 1088-1095. [CrossRef]

13. Nomura, N.; Akai, M. Willingness to pay for green electricity in Japan as estimated through contingent valuation method. Appl. Energy 2004, 78, 453-463. [CrossRef]

14. Haab, T.C.; Mcconnell, K.E. Valuing Environmental and Natural Resources: The Econometrics of Non-Market Valuation; Edward Elgar Publishing: Northampton, UK, 2002.

15. Brent, R.J. Applied Cost-Benefit Analysis, 2nd ed.; Edward Elgar: Cheltenham, UK, 2006.

16. Varian, H.R. Intermediate Microeconomics: A Modern Approach, 9th ed.; Norton \& Company: New York, NY, USA, 2014.

17. Freeman, A.M. The Measurement of Environmental and Resource Values: Theory and Methods; Resources for the Future: Washington, DC, USA, 1992.

18. Garrod, G.; Willis, K.G. Economic Valuation of the Environment; Edward Elgar: Cheltenham, UK, 1999.

19. Mitchell, R.C.; Carson, R.T. Using Surveys to Value Public Goods: The Contingent Valuation Method; Resources for the Future: Washington, DC, USA, 1989.

20. Just, R.E.; Hueth, D.L.; Schmitz, A. The Welfare Economics of Public Policy: A Practical Approach to Project and Policy Evaluation; Edward Elgar: Cheltenham, UK, 2004. 
21. Venkatachalam, L. The contingent valuation method: A review. Environ. Impact Assess. Rev. 2004, 24, 89-124. [CrossRef]

22. Carson, R.T.; Hanemann, W.M. Contingent valuation. In Handbook of Environmental Economics: Valuing Environmental Changes; Maler, K.G., Vincent, J.R., Eds.; Elsevier B.V.: Amsterdam, The Netherlands, 2005; Volume 2, pp. 821-936.

23. Bamwesigye, D.; Hlavackova, P.; Sujova, A.; Fialova, J.; Kupec, P. Willingness to pay for forest existence value and sustainability. Sustainability 2020, 12, 891. [CrossRef]

24. Rodella, I.; Madau, F.A.; Carboni, D. The willingness to pay for beach scenery and its preservation in Italy. Sustainability 2020, 12, 1604. [CrossRef]

25. Shee, A.; Azzarri, C.; Haile, B. Farmers' willingness to pay for improved agricultural technologies: Evidence from a field experiment in Tanzania. Sustainability 2020, 12, 216. [CrossRef]

26. Fisher, A. The conceptual underpinnings of the contingent valuation method. In The Contingent Valuation of Environmental Resources; Bjornstad, D.J., Kahn, J.R., Eds.; Edward Elgar: Cheltenham, UK, 1996; pp. $19-37$.

27. Arrow, K.; Solow, R.; Portney, P.R.; Leamer, E.E.; Radner, R.; Schuman, H. Report of the NOAA panel on contingent valuation. Fed. Regist. 1993, 58, 4601-4614.

28. Johnston, R.J.; Boyle, K.J.; Adamowicz, W.; Bennett, J.; Brouwer, R.; Cameron, T.A.; Hanemann, W.M.; Hanley, N.; Ryan, M.; Scarpa, R.; et al. Contemporary guidance for stated preference studies. J. Assoc. Environ. Resour. Econ. 2017, 4, 319-405. [CrossRef]

29. Hanemann, W.M. Welfare evaluations in contingent valuation experiments with discrete responses. Am. J. Agric. Econ. 1984, 66, 332-341. [CrossRef]

30. Kriström, B. Spike models in contingent valuation. Am. J. Agric. Econ. 1997, 79, 1013-1023. [CrossRef]

31. Yoo, S.-H.; Kwak, S.-J. Using a spike model to deal with zero response data from double bounded dichotomous contingent valuation survey. Appl. Econ. Lett. 2002, 9, 929-932. [CrossRef]

32. Statistics Korea. Korea Statistical Information Service. Available online: http://kosis.kr (accessed on 20 February 2020).

33. Krinsky, I.; Robb, A.L. On approximating the statistical properties of elasticities. Rev. Econ. Stat. 1986, 68, 715-719. [CrossRef]

34. Korea Ministry of Trade, Industry, and Energy. The 8th Basic Plan for Long-Term Electricity Supply and Demand; Korea Ministry of Trade, Industry, and Energy: Sejong, Korea, 2017. (In Korean)

(C) 2020 by the authors. Licensee MDPI, Basel, Switzerland. This article is an open access article distributed under the terms and conditions of the Creative Commons Attribution (CC BY) license (http://creativecommons.org/licenses/by/4.0/). 